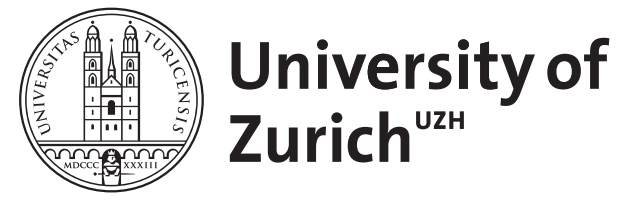
Archive

University of Zurich

University Library

Strickhofstrasse 39

CH-8057 Zurich

www.zora.uzh.ch

Year: 2016

\title{
New developments in family ethics: an introduction
}

Betzler, Monika ; Löschke, Jörg

DOI: https://doi.org/10.1163/17455243-01306001

Posted at the Zurich Open Repository and Archive, University of Zurich

ZORA URL: https://doi.org/10.5167/uzh-169672

Journal Article

Accepted Version

Originally published at:

Betzler, Monika; Löschke, Jörg (2016). New developments in family ethics: an introduction. Journal of Moral Philosophy, 13(6):641-651.

DOI: https://doi.org/10.1163/17455243-01306001 


\section{New Developments in Family Ethics: An Introduction}

Monika Betzler (LMU Munich) and Jörg Löschke (University of Bern)

Over the last three decades, moral philosophy has seen a revived interest in the ethics of personal relationships, especially in the question of so-called associative duties: what do parties of special relationships owe to each other, and on what grounds? How can such associative duties - or special obligations, ${ }^{1}$ as some authors call them - be reconciled with the idea that morality is characterized by the impartial point of view? After all, it is our partiality to our intimates that more often than not seems to conflict with the demands of morality impartially conceived. $^{2}$

It is now common to acknowledge that at least some personal relationships ground such duties. After all, it does not only seem simply wrong to entirely disregard the special demands that friends, partners, or children make on us; we also seem to lose valuable forms of engagement that make up, in part at least, who we are. One strand within moral theorizing has devoted attention to integrating those special duties arising from our personal relationships within an impartial outlook on morality. Another strand of moral theorizing examines more closely the source of such duties and what conditions a personal relationship must fulfill so that partiality to one's friends, partners, or children can be regarded as legitimate. After all, only if the

\footnotetext{
${ }^{1}$ See Diane Jeske, "Special Obligations," in: Edward N. Zalta (ed.): Stanford Encyclopedia of Philosophy (2014). URL=http://plato.stanford.edu/archives/spr2014/entries/specialobligations/.

${ }^{2}$ See John Cottingham \& Brian Feltham, (eds.), Partiality and Impartiality: Morality, Special Relationships, and the Wider World (Oxford: Oxford University Press, 2007) for an overview of the debate about this conflict.
} 
source of associative duties can be located and if partiality to our intimates proves justifiable does it make sense for moral theories to worry about integrating personal relationships and the moral demands they make on us.

One condition for a relationship to ground duties seems to be a relationship-well-being-nexus: a relationship that contributes to the well-being of its participants seems to be a legitimate source of special obligations, and a relationship that does not carries a significant burden of proof, if one wants to uphold the claim that it grounds special obligations. Interestingly, the widely acknowledged fact that personal relationships are constitutive of our well-being has led rival moral theorists, especially consequentialists and Kantians, to reconsider their basic assumptions, and to reformulate their theories to accommodate the special duties that arise from such relationships. To allude to a just few such attempts, many consequentialists took the indirect route and argued along the following lines: ${ }^{3}$ Realizing the value of personal relationships implies responding to special duties that, in turn, demand that we do not constantly deliberate about maximizing general well-being. What we should therefore do is not deliberate about maximizing general well-being, but simply respond to special duties as they arise within personal relationships. In the end, however, it is this default attitude towards fulfilling our special duties that leads to the maximization of general well-being. Kantians, by contrast, try to respond to the worry that the Categorical Imperative and the procedure of universalization cannot accommodate special obligations by interpreting them as instances of

\footnotetext{
${ }^{3}$ See Peter Railton, "Alienation, Consequentialism, and the Demands of Morality," Philosophy and Public Affairs 13 (1984), pp. 134-171; Philip Pettit, “The Consequentialist Perspective," in M. Baron, P. Pettit \& M. Slote, (eds.), Three Methods of Ethics (Oxford: Blackwell, 1997), pp. 92-174.
} 
imperfect duties, that is, as positive duties that allow for discretion over how exactly they are to be fulfilled. ${ }^{4}$

Other moral theories, such as deontology and virtue ethics, which have more natural resources to accommodate the importance of personal relationships, started to develop their views more in light of the challenge that personal relationships pose to moral theorizing. Deontologists are keen to explore the agent-relative reasons and duties to which personal relationships give rise, and which they think stand in contrast to agent-neutral reasons. ${ }^{5}$ Those inspired by virtue ethics delve into the question of what virtues it takes to realize personal relationships, and what character traits personal relationships themselves foster. ${ }^{6}$ They also consider a virtuous character to be a ground for associative duties. ${ }^{7}$

While all these debates start from the assumption that personal relationships are, in principle at least, valuable, and should therefore be accommodated by moral theorizing, they have neither provided an explanation as to what precisely is of value so that associative duties are legitimately generated, nor studied the intricacies of particular kinds of personal relationships. More often than not, they more or less tacitly focus on friendship, but never examine in more detail the ways in which various kinds of relationships differ, and what precisely characterizes

\footnotetext{
${ }^{4}$ Marcia Baron, "Virtue Ethics, Kantian Ethics, and the 'One Thought Too Many' Objection," in M. Betzler, (ed.), Kant's Ethics of Virtue (Berlin/New York: de Gruyter, 2008), pp. 245-
} 277.

5 David McNaughton \& Piers Rawling, “On Defending Deontology,” Ratio 11 (1998), pp. 37-54.

${ }^{6}$ Christopher Heath Wellman, "Friends, Compatriots, and Special Political Obligations," Political Theory 29 (2001), pp. 217-236; Hugh LaFollette, Personal Relationships: Love, Identity, and Morality (Oxford: Blackwell, 1996).

${ }^{7}$ Jennifer Whiting, "Impersonal Friends," The Monist 74 (1991), pp. 3-29. 
them. Also, their main focus has been how moral theories of whatever brand can incorporate relationships and the special duties they engender, and not what it is precisely that grounds the duties to which particular relationships give rise in the first place.

Recently, however, this has started to change. There has been a considerable growth of literature not only on what explains our partiality to others, but also on what characterizes particular kinds of relationships and their specific value. While some claim that it is the shared history of entertaining a particular relationship that grounds special duties, ${ }^{8}$ others think that it is rather the individual value of the person to which one is related that grounds them. ${ }^{9}$ As for the particular value of a relationship - the value that explains why partiality is legitimate rather than unwarranted - the so-called relationship goods view has gained a lot of currency. To the extent that we can be taken to have an interest in these goods we can be said to have reasons for those goods to be realized. To the extent that such goods, however, can only be realized by fulfilling corresponding duties, we have reasons to do what these duties demand of us. Different kinds of relationships can bring about different kinds of goods, and to the extent that such goods can be realized the parties involved have different corresponding duties depending on the goods they are thought to bring about. ${ }^{10}$

The personal relationship that has received the most attention over the last ten years is the family. One of the reasons for this new interest in familial relationships is that the family has undergone dramatic challenges and changes. Couples can be married or unmarried. There can

\footnotetext{
${ }^{8}$ Niko Kolodny, "Love as Valuing a Relationship," The Philosophical Review 112 (2003), pp. $135-189$.

${ }^{9}$ Simon Keller, Partiality (Princeton: Princeton University Press, 2013).

${ }^{10}$ Simon Keller, The Limits of Loyalty (Cambridge: Cambridge University Press, 2007); Jonathan Seglow, Defending Associative Duties (London: Routledge, 2013); Adam Swift \& Harry Brighouse, Family Values (Princeton: Princeton University Press, 2013).
} 
be single parents and same-sex marriages. Children can be genetically related or adopted. And even if they are genetically related they can be procreated in different ways due to procreative technologies. Given this more liberal conception of the family, ${ }^{11}$ and in light of the new technological challenges of procreating and childbearing, the family has become a new focus for those interested in personal relationships and their normative implications.

The family has proved to be a fruitful field of philosophical inquiry whose focus has continued to widen. Regarding its normative implications, philosophers have begun to focus on the parent-child relationship and some of the duties that are implied by this. In particular, they have focused on parental duties - duties that parents have towards their young, ${ }^{12}$ but growing children - and filial duties - the duties that grown children have towards their parents, and the content and ground of those duties. ${ }^{13}$ Another area of investigation is what rights

${ }^{11}$ For a defense of a liberal view of the family, see David Archard, The Family. A Liberal Defense (Basingstoke: Palgrave Macmillan, 2010).

12 Joel Feinberg, "The Child's Right to an Open Future," in W. Aiken \& H. LaFollette, (eds.), Whose Child? Children's Rights, Parental Authority, and State Power (Totowa, NJ: Rowman \& Littlefield, 1980); Matthew S. Liao, "The Right of Children to be Loved," The Journal of Political Philosophy 14 (2006), pp. 420-440; Joseph Millum, "How Do We Acquire Parental Responsibilities?," Social Theory and Practice 34 (2008), pp. 74-93; Norvin Richards, The Ethics of Parenthood (New York: Oxford University Press, 2010).

${ }^{13}$ Christina Hoff Sommers, "Filial Morality,” The Journal of Philosophy 83 (1986), pp. 439456; Nancy Jecker, “Are Filial Duties Unfounded?,” American Philosophical Quarterly 26 (1989), pp. 73-80; Simon Keller, "Four Theories of Filial Duties,” The Philosophical Quarterly 56 (2006), pp. 254-274; Jane English, "What Do Grown Children Owe Their Parents?," in O. O’Neill \& W. Ruddick, (eds.), Having Children. Philosophical and Legal Reflections on Parenthood (Oxford: Oxford University Press, 1979), pp. 351-356. 
parents should have with regard to rearing their children and what precisely grounds these rights. This pertains, among other things, to the parental right to raise and educate their children, ${ }^{14}$ and instill values in them. ${ }^{15}$ Conversely, the rights of children - for example with regard to their physical integrity, political participation, and their own future more generally has become another important field of inquiry. Still there are many areas left untouched by current thinking about family relationships. While the bulk of the literature devoted its attention to rights and duties as they arise within an ongoing parent-child relationship, much is still left to be explored with regard to the rights and duties of parents to start such a relationship in the first place. Similarly, the potential responsibilities younger children have towards their parents remains an understudied subject, and there are many other normative intricacies of the family dynamic that await further scrutiny. The papers in this special issue deal with these issues, and thus continue the debate about rights and duties in the broader family context.

Each text can be seen as dealing with the question of rights and duties that are implied by the family in general and the parent-child relationship in particular. This is not to say that these are the only questions worth discussing - ontological questions, such as the question of what a family is and how it is constituted, as well as questions concerning extended family, are interesting and worthwhile. One might also ask whether the whole approach that attempts to understand the normativity of family relationship in terms of rights and duties is misleading and should be replaced by an analysis of the normativity of family relationships in terms of

\footnotetext{
${ }^{14}$ See, e.g., Norvin Richards, The Ethics of Parenthood (Oxford: Oxford University Press, 2010).

${ }^{15}$ Adam Swift \& Harry Brighouse, Family Values (Princeton: Princeton University Press, 2013). For a critical view on the "comprehensive enrolment" of children see Matthew Clayton, Justice and Legitimacy of Upbringing (Oxford: Oxford University Press, 2006).
} 
virtues or reasons. However, as the papers collected here show, a focus on rights and duties can still cover philosophical ground that has previously been neglected. It is still possible to ask new and interesting questions within that framework. This special issue therefore focuses on the framework of rights and duties to gain further insight into the normative implications of the family.

The papers collected for this special issue thus share the same methodological framework, but each paper applies it from a novel point of view. They not only ask what duties parents or grown children have vis-á-vis the other party. They extend the focus to include the duties of young children to their parents - something that most authors seem to assume does not exist and to the normative dangers that family duties may present. Another important issue is whether rights and duties not only exist once a parent-child relationship is already in place, but whether there might be upstream duties and rights that define what kind of parent-child relationship agents may legitimately have. This special issues aims to highlight these topics regarding the parent-child relationship from a new perspective.

Matthew Liao, in his "Biological Parenting as a Human Right," argues for a (defeasible) right to parent one's biological offspring, and he understands this right as a human right. Liao understands human rights as grounded in the fundamental conditions for pursuing a good life - a life that is spent pursuing valuable, basic activities. The class of basic activities is quite limited: many activities are valuable, and can be highly valued by individuals, such as creating great works of art, or helping others in need. Such activities are valuable and important to individuals. By contrast, basic activities are activities that are important to a human being qua that human being's life as a whole. Given that humans cannot lead good lives without engaging in basic activities, these basic activities ground human rights; more specifically, human rights aim at securing the fundamental conditions - goods, capacities, and options - for engaging in basic activities, and hence for pursuing good lives. 
According to Liao, biological parenting - i.e., the parenting of one's biological offspring - is a basic activity. Biological parenting involves four aspects that jointly explain why it is a basic activity: biological parenting involves creating a new life; the new life is the life of a right-holder; this new life is created with one's own genetic material, and one's own genetic material partly determines the genetic identity of the new individual; and as a biological parent, one witnesses and shapes the growth and development of the new individual. Each of these factors is a good-making feature of biological parenting, and jointly they establish the status of biological parenting as a basic activity.

Because it is a basic activity, humans have a human right to the fundamental conditions for pursuing biological parenting. These conditions include bodily integrity, the liberty and autonomy to plan and pursue biological parenting, and the power to exclude non-parents from trying to be the primary provider for one's biological children. Hence, humans have a human right to procreate and parent their biological children. After developing this human-rights account of parental rights, Liao contrasts it with other prominent accounts of the right to parent one's biological children - the property account, the relationship account, the project account, the gestational account, and the investment account. Liao claims that the human rights account has distinct advantages over these other accounts, and thus constitutes an important and novel option in the literature on parental rights.

Tina Rulli occupies the other end of the argumentative spectrum about the parental right to have children. She argues in her "Preferring a Genetically Related Child" that persons who want to parent a child have a moral (pro tanto) duty to adopt a child, rather than create new life and parent their genetically related child. Her argument proceeds in two steps: first, she motivates the idea that there is a pro tanto duty to adopt; second, she argues that the usual arguments for preferring a genetically related child, rather than an adopted child, fail to justify reasons that outweigh the pro tanto duty to adopt. 
Regarding the first step of her argument, Rulli understands the duty to adopt as a duty of assistance that must be understood analogously to the duty to rescue a child from severe harm if doing so is possible without significant sacrifice. More specifically, the duty to adopt arises from a problem of great magnitude - millions of children are in need of parents - and severity - a lack of parental care impairs the development and well-being of children in need of parents, possibly for the rest of their lives. This problem could be solved, given that there are enough persons who want to parent children and who could adopt children in need of parents, and hence, those persons have a pro tanto duty to adopt, rather than create new children to parent.

Regarding the second step of her argument, Rulli accepts that persons have moral options options to favor their own personal interests over those of others, even if that implies producing less good than they otherwise could. Moral options aim at giving agents the leeway to pursue personal projects - projects that govern their lives and that have positive and nontrivial value that is independent of the person valuing them. Rulli accepts that moral options exist, and that because of such options, persons who do not wish to parent have no duty to adopt. However, moral options do not justify procreating, rather than adopting, because the desire to parent a genetically related child is not supported by reasons that are weighty enough to establish parenting one's genetic child as a life project that is protected by moral options.

To establish this claim, Rulli discusses several reasons why persons might prefer to parent genetic children: the wish to have a child that resembles them physically, the wish to have a child who bears a family resemblance, the wish to have a child that shows psychological similarity, the wish to create a symbol of one's love to one's partner, the wish to attain some kind of immortality, the view that genetic connection is valuable for its own sake, the value of creating a child, and the value of pregnancy. These reasons, Rulli argues, are too trivial, presuppose the value of genetic connection, are inappropriate in a parental context, or fail to 
make a relevant distinction between genetic and adopted children. Hence, they fail to outweigh the pro tanto reason to adopt; the only exception being a woman's desire to experience pregnancy. This desire, as Rulli maintains, can be satisfied by giving birth to one child, but it fails to justify creating more than one child. Hence, people who want to experience parenthood have a moral duty to adopt children, rather than create children, at least after their first genetic child.

While Liao and Rulli focus on the rights and duties of parents with regard to having children, Keller und Mullin take a somewhat different route. They focus on the existing relationship between parents and children, but do so in new ways that have so far been neglected. While Keller is interested in what can go wrong when it comes to fulfilling one's familial duties and thus devotes himself to the question of how the family context can be a locus of immoral behavior, Mullin examines the equally neglected responsibilities parents have with regard to desired behavior regarding their younger children.

In his "Moral Blackmail and the Family," Simon Keller draws our attention to the phenomenon of moral blackmail. He points to its particular significance in family contexts, e.g. the gender-related power dynamics that operate in family relationships, and how this can be misused - even by public policies. According to Keller, we are confronted with a case of moral blackmail if a person A deliberately performs a wrongful act that changes a person B's situation such that it is wrong for B to fail to do what A wants her to do. To illustrate this, Keller refers to the example of a brother who agrees to take care of his elderly and frail father and bring him to the hospital. Since the brother does not feel like wasting his day with his father in the hospital he leaves a message with his sister telling her that he will not be available and then turns his phone off for the rest of the day. The sister - who does most of the caring for the father - is left with the option of having the father miss an important medical procedure or cancelling her own plans. Keller distinguishes moral blackmail from 
cases of prudential and emotional blackmail. In the case of prudential blackmail, a person's choices are manipulated such that they involve greater harm to herself. In emotional blackmail, a person's choices are made emotionally unacceptable. In moral blackmail, by contrast, a person's choices are manipulated by making her circumstances such that she faces moral demands that she otherwise would not face. The moral blackmailer tries to make her do what he wants her to do by making her alternatives morally unacceptable. Moral blackmail thus turns morality against itself, as Keller claims. The person in question is confronted with moral reasons that arise due to the blackmailer's immoral action, and she has no moral right not to give in. That is, it is the blackmailer's fault that the person now has a duty, but it remains her duty, however unfairly it has been acquired. The "success" of moral blackmailing depends on the victim's moral sensitivity. If the victim is sensitive to particular moral standards and takes herself to be subject to them, she will be more liable to moral blackmailing. With this analysis of moral blackmailing in place Keller shows why it is a moral wrong that is particularly present within families. The family - within which much of our caring for the vulnerable occurs - grounds relationships that generate special moral reasons. The sensitivity of individual family members to these moral reasons and the vulnerability connected to being in a close family bond can more easily be exploited. Divorced parents and grown-up siblings with shared filial duties are cases in point. Keller maintains that state policies that make use of such vulnerabilities are especially open to criticism. If the state fails to provide funding for the transport required by disabled children, for example, and burdens parents with the costs, the duty to provide such transport is shifted onto the parents. This policy qualifies as an instance of moral blackmail to the extent that parents violate a duty towards their disabled children if they do not ensure that they have transport. In no longer receiving funding they are left with a morally unacceptable choice. In a similar vein, traditional gender roles and the allocation of family duties that goes along with them facilitate moral blackmailing. Since women are morally judged much more frequently 
and severely than men when it comes to how much care they provide within the family, they are more vulnerable to being made offers they cannot refuse on moral grounds. They are therefore prone to a distinct kind of moral exploitation. As a result, family relations are a particular locus of moral blackmail.

While Keller's interest lies in immoralities as they arise in close family relationships in particular, Mullin turns to the responsibilities that parents have with regard to their young children - responsibilities to motivate their children to feel grateful, for example, with feeling gratitude in appropriate circumstances being a responsibility that even small children can equally be said to have.

In her "Dependent Children, Gratitude and Respect," Mullin defends the view that dependent children owe their parents gratitude for the care they provide for them under some qualified conditions. Mullin is reluctant to claim that children owe this in the sense of having a duty. She rather points out that children should be motivated to be grateful, and this is a responsibility that falls on parents. One might object that children should not be asked to be grateful for the parental care they receive given that parents have the duty to care for their children anyway. Furthermore, the demand to be grateful might make children feel unduly indebted to their parents. Against these objections Mullin argues for an account of gratitude that emphasizes the significance both of benevolence and of respect and distinguishes gratitude from indebtedness. According to Mullin, gratitude is only morally appropriate in response to benefits and benevolence that manifest respect for the beneficiary, and that must be conveyed for the right reasons and in the right way. But children could not be asked to be grateful if they did not have the capacity for gratitude. Mullin draws from empirical psychology to show that children become capable of being grateful between the ages of seven and ten. In that age range, children develop a sense by which they can evaluate whether they have received a benefit and are able to ascribe intent to the benefactor. Gratitude differs from indebtedness in that the object of gratitude is the altruistic benefactor's benevolence towards 
the well-being of the beneficiary, in part at least, for his own sake. Indebtedness, by contrast, is a feeling that results from expectations that mostly arise for selfish reasons, and that use the beneficiary as a means of fulfilling those expectations.

In addition to the benefit given benevolently, a benefactor must also respect the beneficiary so that gratitude is called for. Against the view that respect is only owed to fully autonomous persons - a view that would preclude younger children from being respected - Mullin argues that even young children have partial autonomy. Respect for a child thus requires attention to what she finds meaningful and what she values and engagement with her on these matters. This does not rule out paternalistic interventions being justified if the child still does not fully appreciate the ramifications of what she values. In such cases of paternalism, gratitude might be called for once the child is more autonomous and able to see the benefit of the paternalistic intervention. To sum up, children's gratitude is appropriate and can thus be demanded if the child (i) is capable of appreciating a benefit as such; (ii) is capable of assessing the motives of the benefactor as benevolent; (iii) feels that she was treated with respect; and if (iv) the benefit was not conveyed in a context of abuse and the beneficiary has no reason to disapprove of it on moral grounds.

Furthermore, Mullin draws our attention to additional reasons why it is desirable to foster gratitude. Gratitude helps to sustain positive relationships, and coheres with other valuable features of relationships, such as trust. This is why it is important to encourage gratitude not only in children but also in adults. If adults are grateful for the benefits children give them they deepen their relationship with them. In addition, adults can be role models for their children in showing gratitude and respect. Mullin concludes that teaching children about gratitude and its moral warrant may be an important moral responsibility for parents.

To be sure, the topics presented in this special issue by no means exhaust the new developments that are currently taking place within family ethics. Still, they can serve as cases in point, however, for a new focus on more intricate moral and immoral issues as they 
become manifest between parents and children. Family ethics is a burgeoning field, and the articles in this special issue manifest this continuing trend. ${ }^{16}$

\footnotetext{
${ }^{16}$ We are grateful to Alexander Bagattini and Moritz Dittmeyer for their helpful comments on earlier versions of this introduction. Many thanks also to Matthew Liao for inviting us to coedit this special issue of the Journal of Moral Philosophy.
} 